\title{
Pricing Model of Self-Service Package
}

\section{Zhuang Rong}

North China Electric Power University, Baoding, Hebei, China

2695277664@qq.com

Keyword: Crowdsourcing; Pricing; Clustering analysis; The clustering center; Latitude and longitude

\begin{abstract}
In recent years, with a massive rise of mobile Internet applications, enterprise the self-help service crowdsourcing platform based on mobile Internet use of network resources for commercial inspection and information gathering. The paper mainly studies the factors that affect pricing in package task, eventually establish a reasonable pricing model, improve the completion of tasks. To obtain pricing rule, the first big data processing, using SPSS software for longitude, latitude and pricing for clustering analysis, it is concluded that the clustering center and clustering center distance and location analysis task thus giving pricing patterns and clustering center task latitude and longitude position and the distance of the three factors of relationship, and then find out the pricing rule, multivariate regression model. But because of the analysis of influence factors is too single, which leads to the unreasonable parts of pricing, the final task can't complete; So, give the pricing, tasks unfinished cause failure.
\end{abstract}

\section{Problem Background}

With the global economic recession and the coming of knowledge economy and information age, the social economy is developing towards globalization. Enterprises are in urgent need of more innovative competitive environment. With the increasing competitiveness and vitality of the business environment, it is difficult for a single enterprise to have the technical knowledge and resources to achieve sustainable innovation. No matter how strong the technical force of an enterprise, it is impossible to have all the resources and technology needed for innovation. "The conservative closed innovation behind closed doors" has not been possible to enable enterprises to gain more competitive advantage, enterprises need to integrate internal and external resources, and form a complete system of open innovation. In recent years, with the mature of mobile network technology, the Internet platform of public packet mode has sprung up on a large scale. More and more enterprises are aware of the advantages of the package model.

"Picture making money" is a typical example of the crowd under the mobile Internet. The user downloads APP, registers as a member of the APP, and then receives a mission to take pictures from APP, and earn a fee to be calibrated by the APP for the task. This self-service service based on mobile Internet Crowdsourcing platform, provide a variety of commercial inspection and information collection for the enterprise, compared with the traditional market research can greatly reduce the cost of investigation, and effectively ensure the authenticity of survey data, shorten the survey period. Therefore, APP has become the core of the platform, and the task pricing in APP is the core element. If the pricing is unreasonable, some tasks will be ignored, which will lead to the failure of commodity inspection. Therefore, the rationality of pricing will directly decide whether the crowdsourcing is successful or not. This paper studies the pricing rule in crowdsourcing tasks.

\section{Research on the Problem}

Find Crowdsourcing tasks and data, through the study of the data has been the end of the mission, combined with location information, and the task of price data, establish the pricing model, using the statistical software SPSS GPS position on the task of clustering analysis, finally obtains the pricing rules of this specific task, and what factors.[7] Then the analysis of task completion, combined with the pricing rules, analysis of the causes of the task is not completed, the original analysis tasks and other factors not related, the interaction between the degree and the influence 
factors and the various factors on the task, taking into account the pricing rule above may be due to the influence factors of setting is too single, resulting in some tasks cannot be completed.

Assume

If the task of the GPS latitude and longitude and tasks to the clustering center distance are the three main factors that affects the pricing.

Assuming pricing other auxiliary factor is the adaptation of the independent variable weights to influence pricing.

Table 1 Symbolic description

\begin{tabular}{cl}
\hline Symbol & Significance \\
\hline $\mathrm{P}$ & Pricing of tasks \\
$\mathrm{X}_{1}$ & The longitude of the task position \\
$\mathrm{X}_{2}$ & The latitude of the task position \\
$\mathrm{X}_{3}$ & $\begin{array}{l}\text { The distance between the location of the task and the center } \\
\text { point } \\
\beta_{i}\end{array}$ \\
$\delta$ & $\begin{array}{l}\text { The weight of independent variables in the law of project } \\
\text { pricing }\end{array}$ \\
\hline
\end{tabular}

\section{Establishing Model and Solving}

The pricing rule of tasks in research data is not related to whether the task is completed or not. Therefore, we need to consider the relationship between longitude and latitude and pricing, and find out the inner relationship between them and solve the model.

First, the tasks and pricing are introduced into the three-dimensional map, and the pricing can be preliminarily determined with the latitude and longitude and the geographical location.

Using statistical analysis software SPSS, the latitude and longitude of data and the price of importing the SPSS data, clustering analysis, obtains four clustering center point, combined with the task location distance clustering midpoint distance solution of undetermined coefficients in the model, determine the pricing rules.

Analysis of reasons for the failure to complete the task, then consider the single factors affecting pricing rule makes the task is completed, not only by the influence of longitude and latitude and missions to the cluster center distance from the point of these three factors, but also with the members to distance, task location task place traffic convenience as well as members of the intensive degree.

\section{Model Establishment}

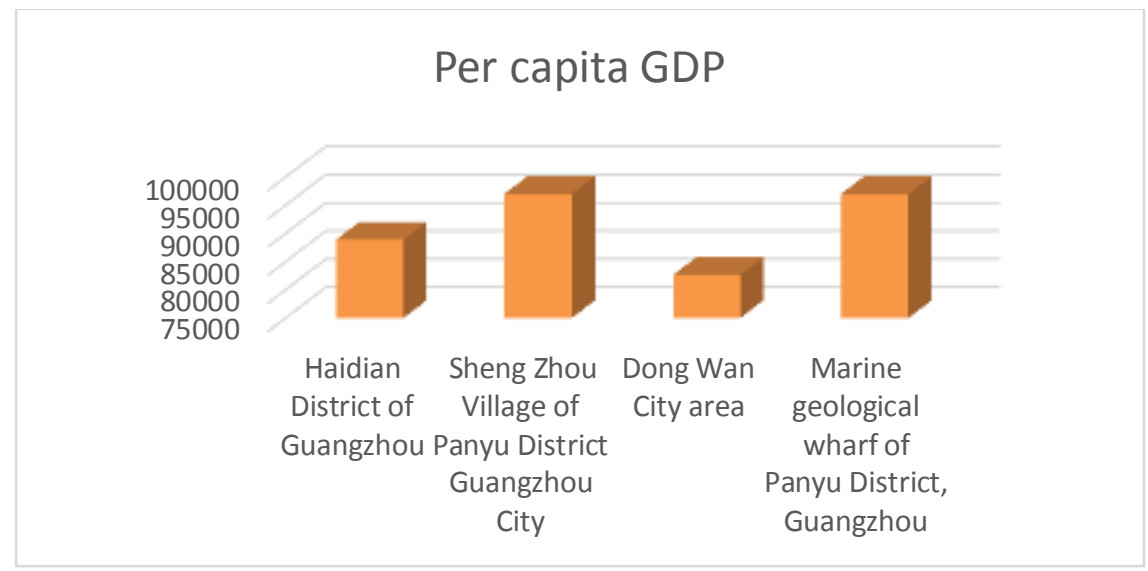

Figure 1. Per capita GDP level of cluster center 
According to the task GPS latitude and longitude of clustering, four clustering centers according to the degree of concentration, considering the pricing is not only affected by the latitude and longitude of the GPS in the task, but also by the task location to the cluster center distance influence, as well as four cluster centers per capita GDP etc.

The histogram is drawn by using EXCEL software, can be found on the four cluster center is not obvious difference of per capita GDP, so you can ignore the effect of GDP on pricing, so the pricing law is formulated and the task of longitude and latitude and the distance between clusters based on.

Therefore, the price P and task GPS latitude X1, task GPS longitude X2 and the distance from the task location to the cluster center are $\mathrm{X} 3$. After MATLAB fitting, it is found that $\mathrm{P}$ and $\mathrm{X} 1, \mathrm{X} 2$ and $\mathrm{X} 3$ are multiple linear regression equations.:

$$
\mathrm{P}=\sum_{i=1}^{3} \beta_{\mathrm{i}} X_{i}+\delta
$$

\section{Model Solution}

The expression of clustering after clustering by clustering:

$$
\mathrm{P}=0.275299807 X_{1}+0.52840255 X_{2}+1.082452765 X_{3}-1.149469002
$$

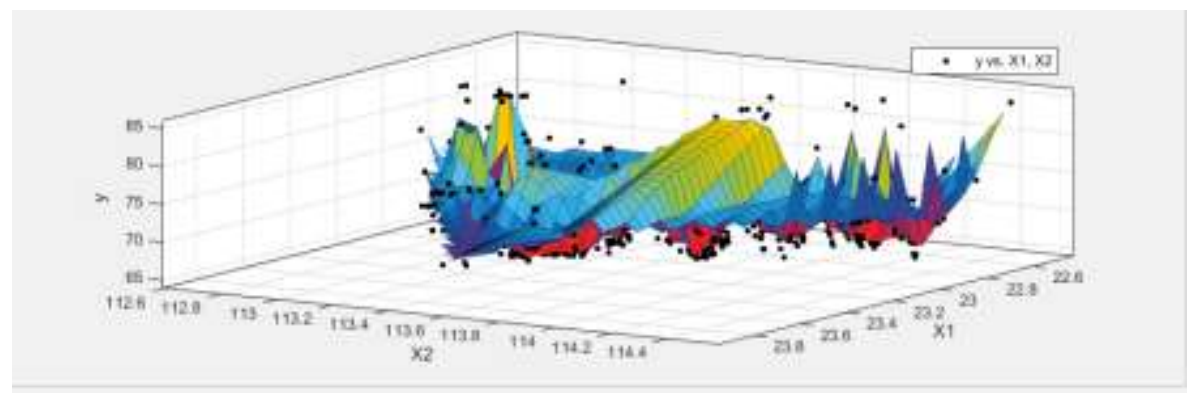

Figure 2. Model after clustering

\section{The Reasons for not being Completed in a Task}

Whether the task is completed is not only affected by the longitude, latitude, and the distance from the task location to the cluster center, but also from the three factors to the location of the mission. Because of the price, membership is generally according to the ratio of price and distance to determine whether to do the task, the same task is little difference in the different regions of the price, and when the distance increases, the ratio of price and distance will decrease, members of long-distance missions will therefore in fourth in the loss outweighs the gain., ask. The members of the position as the location for the task. The convenience of the location of the task and the intensity of the membership will also affect the pricing. [11]

\section{Reference}

[1] E.J. Xia, X.W. Zhao, S. Li: Overseas public package research status and trend [J]. technology economy, 2015, 34 (1): 28-36. (In Chinese)

[2] J. Yan, S.P. Chi, C. Yu: Based on activity of public packet workers reputation model [J]. computer applications, 2017, 37 (7): 2039-2043. (In Chinese)

[3] H.Z. Shen: Competency based emergency information management for public package participants selection model research [J]. library science research, 2017 (13): 93-100. (In Chinese)

[4] A.J. An, J. Zhai: Software Crowdsourcing participation factors analysis and forecasting model [J]. computer system application, 2015, 24 (10): 9-16. (In Chinese) 
[5] C.Q. Wu, X. Hung: An improved Bias crowdsourcing model based on community discovery [J]. Journal of Xiangtan University, 2015 (4): 87-91. (In Chinese)

[6] S.F. Lin, F. Lin: Public package definition, model research, development and Prospect [J]. science and technology management research, 2015, V.35; No.326 (4): 212-217. (In Chinese)

[7] H.Q. Han, G.J. Zhao: Research premise and conceptual model construction of G.J. Zhao. Based on the perspective of service leading logic, research on technology management, 2014 (18): 185-191. (In Chinese)

[8] L.B. Zhang, F.P. Zhong, H. Tu: Crowdsourcing summary of the progress and Countermeasure of [J]. science and technology, 2012, 29 (6): 154-160. (In Chinese)

[9] J.H. Fen, G.L. Li, J.H. Feng: A summary of the technical research on crowdsourcing [J]. Journal of computer science, 2015 (9): 1713-1726. (In Chinese)

[10] Webb L M. Online Research Methods, Qualitative[M]// The International Encyclopedia of Communication Research Methods. 2017.

[11] S.F. Lin: Research on crowdsourcing performance improvement based on the network of public packet participants [D]. Huaqiao University, 2015. (In Chinese) 